\title{
CORRESPONDENCE
}

\section{Language barriers in teleophthalmology}

(c) The Author(s), under exclusive licence to The Royal College of Ophthalmologists 2021

Eye (2022) 36:1335; https://doi.org/10.1038/s41433-021-01654-3

\section{TO THE EDITOR:}

Thanks is given to Scanzera, Kim, and Paul Chan for their editorial regarding inequities in healthcare that were underscored given the heavy usage of teleophthalmology during the COVID-19 pandemic [1]. It is worth adding to the discussion the importance of ensuring proper language interpretation services on teleophthalmology platforms for patients who are able to adequately access the service. Certainly, it is possible that inability to access proper language interpretation services on teleophthalmology platforms further exacerbates inequities in healthcare. It is apparent that language-concordant care improves healthcare outcomes $[2,3]$.

It is well established in healthcare that professional language interpretation services have positive effects on overall satisfaction with care [4]. Although many institutions have added professional language interpretation services as a routine part of their inperson clinical practice, it is worth investigating if teleophthalmology platforms have been able to provide a comparable service to all patients. In addition, teleophthalmology developers may also consider ensuring that written text on the application itself is available in different languages.

Even if a patient has the ability to access a teleophthalmology platform, a lack of proper interpretation services may ultimately culminate in improper delivery of patient care. Clinicians should be mindful if the teleophthalmology service employed in their practice is able to provide a professional medical interpreter to join the encounter if the patient is not proficient in the dominant language. Discussion of language barriers in the realm of teleophthalmology is essential in pursuit of creating appropriate solutions. It is important to continue the conversation regarding the barriers associated with adequate use of teleophthalmology in the effort to enhance access to high quality healthcare, especially during the COVID-19 pandemic.

\author{
Gabriella Schmuter (iD) ${ }^{1 凶}$ \\ ${ }^{1}$ City University of New York School of Medicine, New York, NY, USA. \\ 凶email: gschmut000@citymail.cuny.edu
}

\section{REFERENCES}

1. Scanzera AC, Kim SJ, Paul Chan RV. Teleophthalmology and the digital divide: inequities highlighted by the COVID-19 pandemic. Eye 2021;35:1529-31.

2. Diamond L, Izquierdo K, Canfield D, Matsoukas K, Gany F. A systematic review of the impact of patient-physician non-English language concordance on quality of care and outcomes. J Gen Intern Med. 2019;34:1591-606.

3. Al Shamsi H, Almutairi AG, Al Mashrafi S, Al Kalbani T. Implications of language barriers for healthcare: a systematic review. Oman Med J 2020;35:e122.

4. Karliner LS, Jacobs EA, Chen AH, Mutha S. Do professional interpreters improve clinical care for patients with limited english proficiency? A systematic review of the literature. Health Serv Res. 2007;42:727-54.

\section{AUTHOR CONTRIBUTIONS}

G.S. was entirely responsible for the conception of this letter, drafting the work, and providing references.

\section{COMPETING INTERESTS}

The author declares no competing interests.

\section{ADDITIONAL INFORMATION}

Correspondence and requests for materials should be addressed to G.S.

Reprints and permission information is available at http://www.nature.com/ reprints

Publisher's note Springer Nature remains neutral with regard to jurisdictional claims in published maps and institutional affiliations. 